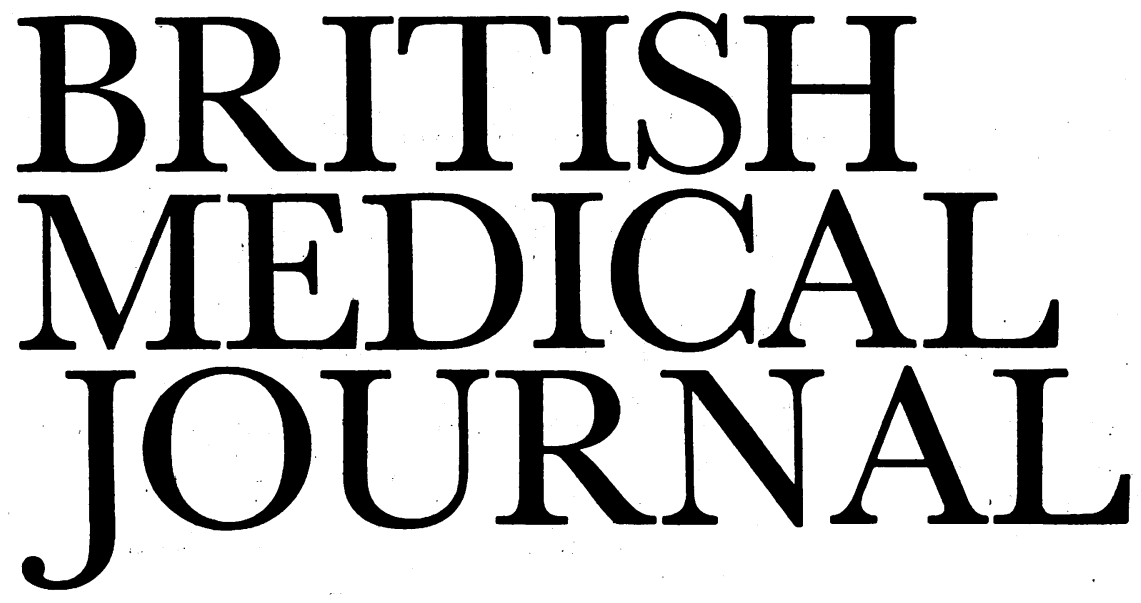

LONDON, SATURDAY 18 JULY 1987

\title{
Effectiveness of treatment for infertility
}

Many doctors and lay people think that the great technical advances in the past 20 years in treating infertility have led to high success rates in treatment, ${ }^{1}$ but this is a myth. Subspecialists often do not appreciate the limited therapeutic impact of the many diagnostic tests, ${ }^{2}$ and many couples achieve pregnancy independently of medical intervention.

The most successful treatment is for patients with hypothalamic or hyperprolactinaemic amenorrhoea: four fifths will conceive after treatment with gonadotrophin or releasing factor. ${ }^{3}$ But as they constitute only $7 \%$ of all infertile couples ${ }^{4}$ the total impact of this treatment is small. Other causes of anovulation account for some $14 \%$ of subfertility, and at most half of these patients will conceive after treatment with clomiphene or gonadotrophin. ${ }^{5}$ Thus about $13 \%$ of all infertile couples will conceive as a result of endocrine treatment of the woman. Tubal damage and blockage (apart from reversal of sterilisation) account for around $14 \%$ of cases of infertility in Britain, ${ }^{4}$ and perhaps $15 \%$ of these will conceive after tubal surgery. Thus at most $15 \%$ of patients with non-iatrogeneic infertility might conceive as a result of treating tubal damage or anovulation.

About a third of cases of infertility are caused by a low count of motile sperm - oligozoospermia (or more correctly oligoasthenoteratozoospermia). ${ }^{4}$ Many of these patients will conceive without treatment. Hormonal treatment (with clomiphene, tamoxifen, or gonadotrophins) will increase the sperm count but not the fertility rate in such men. ${ }^{6}$ Gonadotrophin treatment is effective only in hypothalamic or pituitary eunuchs, and as these account for only $2 \%$ of cases of male infertility ${ }^{4}$ the overall contribution of this treatment is insignificant. All other treatments-such as giving vitamin $\mathrm{C}$, ligating varicose veins, or advising avoidance of hot baths, etc-are of no established value. ${ }^{78}$

About $8 \%$ of cases of infertility are caused by male sperm antibodies, ${ }^{4}$ and conception may occur in perhaps just under a third of these after hazardous immunosuppressive treatment. ${ }^{9}$ Again, therefore, the overall impact of this treatment is small, raising the cumulative total to no more than $18 \%$. The treatment of other putative causes of infertility is unproved. There is no controlled evidence that various hormonal treatments for the nebulous diagnosis of corpus luteal insufficiency are of benefit. ${ }^{10}$ Other treatments such as artificial insemination by husband, both intrauterine and intracervical, in cases of poorly explained infertility or

(C) BRITISH MEDICAL JOURNAL 1987. All reproduction rights reserved. oligozoospermia are ineffective. ${ }^{112}$ Treating endometriosis does not increase the chances of conception, and most authorities have concluded that, with the exception of very severe cases, the association between endometriosis and subfertility is not simple cause and effect. ${ }^{13}{ }^{14}$ Psychotherapy has been recommended for unexplained subfertility and cervical mucous hostility and has been successful in uncontrolled studies. ${ }^{15}$ We would be surprised if psychotherapy did not have some positive impact given the highly abnormal psychological profiles of patients with unexplained infertility compared with, say, those with tubal blockage. ${ }^{16}{ }^{17}$ Nevertheless, this treatment is not widely used or available. Thus we must conclude that less than $18 \%$ of the infertile population may conceive as a result of medical intervention. This is a generous estimate, and some patients may be rendered infertile through investigations for infertility. ${ }^{18} 19$

What about in vitro fertilisation and the new techniques such as gamete intrafallopian transfer? At least $30 \%$ of people with blocked tubes will conceive after in vitro fertilisation, ${ }^{20}$ and if this technology were widely available it would raise the overall success rate of treating infertility to around $23 \%$. These new technologies are also effective in around $15 \%$ of patients with unexplained infertility and in a smaller fraction of those with oligozoospermia. We could therefore increase the overall success of the infertility services to about $34 \%$ if in vitro fertilisation and gamete intrafallopian transfer were widely available on the National Health Service-a doubling of the success rate for medical intervention. We believe that increasing the availability of in vitro fertilisation would be more cost effective for alleviating total suffering than most other surgical procedures and many diagnostic tools which provide precision that cannot be matched by the results of treatment.

Nevertheless, some two thirds of the $5-10 \%$ of couples who cannot conceive spontaneously would remain childless even if the new technology were widely available. Two forms of research are needed to help such patients. Firstly, we need a much more scientific approach to infertility. In 1983 only three articles in Fertility and Sterility had appropriate randomised experimental designs, ${ }^{21}$ and it was many years before treatments such as tamoxifen for oligozoospermia, varicocele ligation, and clomiphene for unexplained infertility or presumed corpus luteal insufficiency were subjected to controlled analysis. ${ }^{3622}$ There are still no published 
randomised studies of the widely used immunosuppressive regimens for treating sperm antibodies, though a study is now under way. No controlled trials of different methods of in vitro fertilisation have used childbirth as the end point. Thus the first advance must be to organise randomised controlled trials to test widely used treatments. In order to avoid the type II error large cohort sizes will be required and multicentre collaboration will be essential. National organisations such as the British Fertility Society will have a large part to play.

The second form of research must be basic physiological and biochemical studies. The causes of many unexplained cases of subfertility and the reason for the poor implantation rates with in vitro fertilisation will emerge from basic biochemical research, and endocrinologists are turning their attention from measurement of hormone concentrations in peripheral blood to the subtleties of endometrial, ovarian, and fallopian tube biochemistry. ${ }^{23-25}$ The news for male oligozoospermia, still the commonest known cause of subfertility in Europe, is more depressing. The first important lesson was that a low sperm count is merely a marker for sperm function. Fertility can be achieved with very low sperm numbers in vitro, and hypothalamic eunuchs with normal spermatogenesis often achieve pregnancy in the early phases of gonadotrophin treatment when the spermatozoa first appear. Oligozoospermia therefore implies a generalised defect in sperm function. Oligospermic patients seldom conceive after in utero sperm insemination, ${ }^{11} 12$ but closer admixture of sperm and egg with in vitro fertilisation or gamete intrafallopian transfer may result in successful fertilisation. ${ }^{2627}$ The zona pelucidum forms a barrier to severely defective sperm, which may be overcome by periviteline microinjection of sperm heads; the practical importance of this observation is, however, limited, and such sperm might carry a defective genetic message that could impede implantation and subsequent embryonic development. ${ }^{27}$ Further improvements in managing male infertility will therefore depend on a deeper understanding of chromosome function and gene transcription in normal and defective sperm. ${ }^{28}$

RICHARD J LILFORD Professor of obstetrics and gynaecology

MAUREEN E DALTON Lecturer/senior registrar

Department of Obstetrics and Gynaecology,

St James's University Hospital,

Leeds LS9 7TF

1 Winston R. Infertility. A sympathetic approach. London: Martin Dunitz, 1986:1.

2 Burslem RW, Osbourne JC. Unexplained inferility. Br Med 7 1986;292.576-7.

3 Katayama KP, Kap-Soon JU, Manuel M, Jones GS, Jones H. Computer analysis of etiology and pregnancy rate; in 636 cases of primary infertility. Am $\mathcal{f}$ Obstet Gynecol 1979;135:207-14.

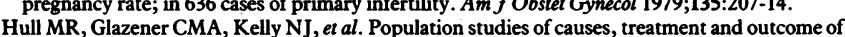
infertility. Br Med f 1985;291:1693-7.

5 Whitelaw MJ, Kalman CF, Grams LR. The significance of the high ovulation rate versus the low pregnancy rate with Clomid. Am $\mathcal{F}$ Obstet Gynecol 1970;107:865-9.

6 Schill WB. Medical treatment of male infertility. In: Insler V, Lunenfeld B, eds. Infertility male and female. Edinburgh: Churchill Livingstone, 1986:533-73.

7 Aafjes JH, Van der Vijver JCM. Fertility of men with and without varicocoele. Fertil Steril 1985;43:901-6.

8 Weiss DB, Rodriguez-Rigau L, Smith KD, Steinberger E. Ledgdig cell function on oligosperimic men with varicocoeles. $f$ Urol 1978;120:427-30.

9 Hendry W, Goldstraw P, Husband JE, Barrett A, McElwain JJ, Peckham MJ. The results of intermittent high dose steroid therapy for male infertility due to antisperm antibodies. Fertil Steril 1981;36:4-7.

10 Wathen NC, Perry L, Lilford RJ, Chard T. Interpretation of single progesterone measurements in the diagnosis of anovulation and defective luteal phase: Observations on analysis of the normal the diagnosis of anovulation and

11 Moghissi KS. Some reflections on intrauterine insemination. Fertil Steril 1986;4:13-5.

12 Allen NC, Herbert CM, Maxson WS, Rogers BJ, Diamond MP, Wentz AC. Intrauterine insemination: a critical review. Ferril Steril 1985;44:569-80.

13 Dmowski WP, Rao R, Scommegna A. The luteinised unruptured follicle syndrome and endometriosis. Fertil Steril 1980;33:30-4.

14 Drake TS, O'Brien WF, Ramwell PW, Metz SA. Peritoneal fluid thromboxane $B_{2}$ and 6 ketoprosta- glandin $F_{2}$ in endometriosis. Am $\mathcal{F}$ Obstet Gynecol 1981;140:401-6.
15 Rutherford RN, Banks L, Coburn WA, Zaffiro FH, Williams J. The treatment of psychological factors in anovulation. Fertil Steril 1961;12:55-9.

16 Bromham DR, Lilford RJ, Balmer B, Wright S. Psychometric evaluation of distress and anxiety in infertile couples. In: Teoh ES, Ratnam SS, Lim SM, eds. XII World congress on fertility and sterility, Singapore, 26-31 October, 1986. Handbook of abstracts III. Singapore: Obstetrical and Gynaecological Society of Singapore, 1986:674.

17 Dennerstien L, Morse C. Psychological issues in IVF. Clin Obstet Gynaecol 1985;12:835-46.

18 Vere MF, Joyce DN. Luteal function in patients seeking AID. Br Med f 1979;ii:100.

19 McBain JC, Evans J, Pepperell RJ, Robinson HP, Smith MD, Brown JD. An unexpectedly high rate of ectopic pregnancy following induction of ovulation with human pituitary and chorion gonadotrophin. Brf Obstet Gynaecol 1980;87:5-9.

20 Whitehead MI, Campbell S, Parsons J, et al. The King's College Hospital IVF programme 198285. Fertil Steril 1986;45(suppl 355):122S.

8live EL. Analysis of clinical fertility trials. Methodological review. Fertil Steril 1986;45:157-69.

Jansen RPS. Ens of clinical fertility trials. Methodological review. Fertil Steril 1986;45:157-69. ansen RPS. Endocrine response in the female genital tract. In: Shearman
reproductive endocrinology. Edinburgh: Churchill Livingstone, 1986:109-64.

23 Johanisson E. Cyclical changes in endometrial morphology. In: Shearman R, ed. Clinical reproductive endocrinology. Edinburgh: Churchill Livingstone, 1985:129-32.

24. Batra S, Helm G, Owman C, Sjoberg NO, Walles B. Female sex steroid concentrations in the ampullary and isthmic regions of the human fallopian tube: their relationship to plasma concentration during the menstrual cycle. Am F Obstet Gynecol 1980;136:986-91.

25 Garfield RE, Hayashi RH. Presence of gap junction in the myometrium of women during various stages of menstruation. Am f Obstet Gynecol 1980;138:569-74.

26 Yovich J, Stonger J, Yovich J. The management of oligospermic infertility by in vitro fertilisation. Ann NY Acad Sci 1985;442:276-86.

7 DeKretser DM, Yates C, Kovacs GT. The use of IVF in the management of male infertility. Clin Obstet Gynaecol 1985;12:767-74.

28 Rudak E, Jacobs P, Yanagimachi R. Direct analysis of the chromosome constitution of human spermatozoa. Nature 1978;274:911-3.

\section{The wide range of chlamydial infection}

What's in a name? Shakespeare was certainly not thinking of $\vec{\infty}$ chlamydiae when he penned these words, but Juliet's $\subseteq$ question could well apply to the taxonomic confusion that has beset this group of organisms. 'As Ward has pointed out, $\vec{\otimes}$ the term chlamydia (a cloak) is a misnomer': 80 years ago . Halberstaedter and von Prowazek first observed inclusions of the trachoma agent in infected ocular material and, thinking they were protozoans, gave the name chlamydozoaceae to these "mantled animals." ${ }^{3}$ The chlamydiae were later again wrongly classified as viruses, and terms such as bedsoniae and trachoma inclusion conjunctivitis (Tric) agents were formulated, but eventually the controversy over whether the organism was a virus or bacterium was resolved by Moulder in $1966 .{ }^{4}$ Is is incontrovertibly a bacterium with affinities to the Gram negative cocci, ${ }^{5}$ and the two species of the genus are Chlamydia trachomatis and $C$ psittaci.

The clinical features of chlamydial infection can cause equal confusion as their range is wide and continues to expand, although evidence on related conditions goes back to antiquity. Ridgeway noted that a reference to trachoma is to 9 be found in the Ebers papyrus (1500 BC), where cicatrising $N$ eye disease and its treatment with copper salts is described. ${ }^{5}$ Even earlier accounts of the disease and its treatment have been listed by Duke-Elder-China in the twenty seventh century BC, Sumeria in the twenty first, and Egypt in the nineteenth. ${ }^{6}$ In northern Europe trachoma was unknown until the middle ages, when it was introduced by the Crusaders returning from Palestine; during the nineteenth and early twentieth centuries the disease became widespread in Europe, especially around the Mediterranean. The causative organism, $C$ trachomatis, is responsible for the world's commonest eye disease; it affects 500 million people, mainly in the rural communities of Africa, the Middle East, and the Far East.?

$C$ trachomatis is also common in the developed world, causing various genital and oculogenital infections. Associations have been reported with non-gonococcal and postgonococcal urethritis, cervicitis, salpingitis, epididymitis, 